\title{
Effects of exogenous indole-3-acetic acid on the photosynthesis characteristics of lettuce under cadmium stress
}

\author{
Guochao Sun ${ }^{1}$, Yan Wang ${ }^{2}$, Xiaohan $\mathrm{Wei}^{2}$, Yunying Xiao' ${ }^{2}$, Xiangting $\mathrm{Xu}^{2}$ and Yi Tang ${ }^{*}$ \\ ${ }^{1}$ Institute of Pomology and Olericulture, Sichuan Agricultural University, Chengdu, Sichuan, 611130, China \\ ${ }^{2}$ College of Horticulture, Sichuan Agricultural University, Chengdu, Sichuan, 611130, China
}

\begin{abstract}
IAA (indole-3-acetic acid), can regulate plant growth and development, and it can involve in regulation of abiotic stresses. In the present study, the effects of spraying different concentrations $(0,25,50$, 100 and $200 \mu \mathrm{mol} / \mathrm{L}$ ) of IAA on the photosynthesis physiology in lettuce were investigated. The lettuce (Lactuca sativa) exposed to cadmium (Cd) exhibited a substantial change in photosynthetic pigment content and photosynthetic parameters. Spraying exogenous IAA resulted in alleviating the inhibitory of Cd toxicity to lettuce. The photosynthetic pigment content in shoot of lettuce increased by spraying with IAA compared with the $\mathrm{Cd}$ treatment alone. Cd stress caused reductions $(P<0.05)$ in $\mathrm{Pn}$ and Ls, respectively, whereas Gs, $\mathrm{Ci}$, and $\operatorname{Tr}$ were increased, compared with the control. Spraying exogenous IAA resulted that the Pn increased and the Ls, Gs, Ci, Tr showed different trend. Therefore, spraying IAA effectively changed the photosynthetic pigment contents and photosynthesis parameters in lettuce.
\end{abstract}

\section{Introduction}

Currently, heavy metal contamination of soil is a significant worldwide environmental problem, and the cadmium $(\mathrm{Cd})$ contamination levels are higher than the other metals [1]. Lettuce (Lactuca sativa), the global commercial production reaches up to 23.6 million metric tons in 2010 [2]. Due to limited availability of arable land and the high market demand for vegetables around the world, lettuce is frequently cultivated under unfavourable conditions [3]. The absorption of $\mathrm{Cd}$ not only inhibits plant growth and development, but also has the potential to affect human health [4]. Lettuce plants grown in Cd-contaminated soil can easily absorb $\mathrm{Cd}$ and rapidly transport $\mathrm{Cd}$ to their shoot [5]. The great value and high accumulation ability of lettuce make it essential to protect it from $\mathrm{Cd}$ contamination.

Indole-3-acetic acid (IAA), as a signal hormone in higher plants, regulates the growth and development of plants, and has a crucial function in stress resistance [6]. And now, some studies have demonstrated IAA alleviated Cd-induced toxicity on plants. The IAA (10 $\mu \mathrm{mol} / \mathrm{L}$ ) is sprayed on eggplant seedlings, and increases biomass and decreases the $\mathrm{Cd}$ content of root and shoot, grown in $3 \mathrm{mg} / \mathrm{kg}$ and $9 \mathrm{mg} / \mathrm{kg} \mathrm{Cd}$ contaminated soil [7]. However, there is no study to investigate the effect of exogenous IAA on photosynthesis characteristic in lettuce under $\mathrm{Cd}$ stress.

Taking the above facts into consideration, the effect of different concentrations of IAA on the photosynthetic pigment contents and photosynthesis parameters of lettuce under $\mathrm{Cd}$ stress were studied.

\section{Materials and methods}

\subsection{Materials}

Seeds of "Glass lettuce" were purchased from the Chengdu seed station. This cultivar shows high purity, good quality, good resistance and suitable growing period (50 d from sowing to harvest), IAA was purchased from Sigma-Aldrich (St. Louis, MO, USA).

\subsection{Experimental design}

The pot experiment was conducted at the Institute of Pomology and Olericulture of Sichuan Agricultural University from February 2017 to June 2017. In February, the uniform size of lettuce seeds were sterilized in $10 \%$ $\mathrm{H}_{2} \mathrm{O}_{2}(\mathrm{v} / \mathrm{v})$ for $10 \mathrm{~min}$, and then rinsed with ultrapure water. The sterilized seeds were placed evenly in culture dishes lined with moist filter paper and germinated in an artificial incubator at $20^{\circ} \mathrm{C}$. When the radicle length was $5 \mathrm{~mm}$, the germinated seeds were sown in an enamel tray containing clean sand and grown in an incubator maintained at $23{ }^{\circ} \mathrm{C} / 18{ }^{\circ} \mathrm{C}$ (light/dark) under light intensity of $200 \mu \mathrm{mol} /\left(\mathrm{m}^{-2} \cdot \mathrm{s}^{-1}\right)$ and photoperiod of 14 $\mathrm{h} / 10 \mathrm{~h}$ (light/dark). The 1/2 Hoagland nutrient solution was applied every day.

After $15 \mathrm{~d}$ of culturing, the lettuce plants with four completely unfolded leaves were transplanted into plastic pots $(10 \mathrm{~cm}$ in diameter and height) filled with clean sand, two seedlings per pot. Every three pots were placed in a plastic tray $(8 \mathrm{~cm}$ in height $)$ filled with Hoagland's nutrient solution, and the nutrient solution was replaced

\footnotetext{
*Corresponding author’s e-mail: 95459425@qq.com
} 
at $2 \mathrm{~d}$ intervals. $3 \mathrm{~d}$ after transplanted, the cultivation conditions were changed to the Hoagland's nutrient solution with $10 \mathrm{mg} / \mathrm{L} \mathrm{CdCl} \cdot 2.5 \mathrm{H}_{2} \mathrm{O}$. Lettuce seedlings were cultivated in nutrient solution without $\mathrm{Cd}$ as the control. At the same time, the leaves of the Cd-treated lettuce seedlings were sprayed with different concentrations of IAA solution $(0,25,50,100$, or 200 $\mu \mathrm{mol} / \mathrm{L})$ at 09:00. The control and $\mathrm{Cd}$ treatment alone were sprayed with distilled water. The IAA solutions were applied three times at $2 \mathrm{~d}$ intervals. Each treatment consisted of three pots (on plastic trays) and which was replicated three times. The pots were kept under ambient environmental conditions with natural sunlight and temperature (from March to April). Air temperature ranged between $23 \pm 2.5^{\circ} \mathrm{C}$ (day) and $16 \pm 2.5^{\circ} \mathrm{C}$ (night). Relative humidity varied from $65 \%$ to $84 \%$. The lettuce was harvested during the period of organ formation (40 days after transplanted).

\subsection{Determination of Photosynthetic Pigment Contents and Photosynthetic Parameters}

The second and third functional leaves from the shoot top $(n=3)$ were used to determine the net photosynthetic rate $(\mathrm{Pn})$, stomatal conductance $(\mathrm{Gs})$, transpiration rate $(\mathrm{Tr})$, intercellular $\mathrm{CO} 2$ concentration $(\mathrm{Ci})$ and stomatal limitation (Ls) using a LI-6400XT portable photosynthesis system (LI-COR, Lincoln, NE, USA) at $25{ }^{\circ} \mathrm{C}$ with endogenous light intensity of 1000 $\mu \mathrm{mol} /\left(\mathrm{m}^{-2} \cdot \mathrm{s}^{-1}\right)$ and $\mathrm{CO}_{2}$ concentration of $400 \mu \mathrm{mol} / \mathrm{L}$. Ls was calculated as one minus ( $\mathrm{Ci}$ divided by $\mathrm{Ca}$ ), the $\mathrm{Ca}$ is concentration of the carbon dioxide in air. Photosynthetic pigment contents were determined using the method of Hao, Cang and $\mathrm{Xu}$ [8]. Chopped leaves (0.2 g) were soaked in $20 \mathrm{~mL}$ of $80 \%$ acetone overnight. The absorbance of the extracts was determined at various wavelengths (663, 645, and $480 \mathrm{~nm})$ using a spectrophotometer (PerkinElmer, Norwalk, CT, USA).

\subsection{Statistical Analyses}

All data were processed with Excel 2010 software and analysed by means of one-way ANOVA in combination with the least significant difference (LSD) test using SPSS 20.0 statistical software (IBM Corporation, Armonk, NY, USA). Significance was assessed at the 5\% level of probability.

\section{Results}

\subsection{Photosynthetic Pigment Contents}

$\mathrm{Cd}$ stress significantly reduced the contents of chlorophyll a, chlorophyll $\mathrm{b}$, and total chlorophyll in the leaf (Table 1). The inhibitory effect of $\mathrm{Cd}$ on lettuce was alleviated by application of IAA. Treatment with IAA concentrations of 50,100, and $200 \mu \mathrm{mol} / \mathrm{L}$ significantly increased the chlorophyll a content in the leaves by $11.28 \%(P<0.05), 14.79 \%(P<0.05)$, and $12.20 \%(P<$ $0.05)$, respectively, compared with $\mathrm{Cd}$ treatment alone, and these contents were not significantly different from the control. The effect of IAA on chlorophyll b content and total chlorophyll in the leaves were similar to that of chlorophyll a content, and the highest content of chlorophyll $\mathrm{b}$ and total chlorophyll in the leaves were observed in the $100 \mu \mathrm{mol} / \mathrm{L}$ IAA treatment, which were $22.22 \%(P<0.05)$ and $16.01 \%(P<0.05)$ higher than $\mathrm{Cd}$ treatment alone, respectively. Under Cd stress, when IAA concentration exceeded $50 \mu \mathrm{mol} / \mathrm{L}$, there was no significant difference in chlorophyll contents that were observed between the treatments and the control, but all of them were remarkably higher than Cd treatment alone. No significant difference in carotenoid content was observed among all treatments.

Table 1. Effects of exogenous IAA on photosynthetic pigment contents of lettuce under Cd stress.

\begin{tabular}{cccccc}
\hline Treatment & $\begin{array}{c}\text { Chlorophyll a } \\
(\mathrm{mg} / \mathrm{g})\end{array}$ & $\begin{array}{c}\text { Chlorophyll b } \\
(\mathrm{mg} / \mathrm{g})\end{array}$ & $\begin{array}{c}\text { Total chlorophyll } \\
(\mathrm{mg} / \mathrm{g})\end{array}$ & $\begin{array}{c}\text { Chlorophyll a/b } \\
\text { ratio }\end{array}$ & $\begin{array}{c}\text { Carotenoid } \\
(\mathrm{mg} / \mathrm{g})\end{array}$ \\
\hline Control & $0.78 \pm 0.00 \mathrm{a}$ & $0.23 \pm 0.01 \mathrm{a}$ & $1.01 \pm 0.01 \mathrm{a}$ & $3.39 \pm 0.01 \mathrm{~d}$ & $0.20 \pm 0.01 \mathrm{a}$ \\
$\mathrm{Cd}+0 \mu \mathrm{mol} / \mathrm{L} \mathrm{IAA}$ & $0.66 \pm 0.03 \mathrm{c}$ & $0.18 \pm 0.01 \mathrm{c}$ & $0.84 \pm 0.02 \mathrm{c}$ & $3.67 \pm 0.01 \mathrm{a}$ & $0.19 \pm 0.01 \mathrm{a}$ \\
$\mathrm{Cd}+25 \mu \mathrm{mol} / \mathrm{L} \mathrm{IAA}$ & $0.68 \pm 0.02 \mathrm{bc}$ & $0.19 \pm 0.01 \mathrm{bc}$ & $0.87 \pm 0.03 \mathrm{bc}$ & $3.58 \pm 0.01 \mathrm{~b}$ & $0.18 \pm 0.00 \mathrm{a}$ \\
$\mathrm{Cd}+50 \mu \mathrm{mol} / \mathrm{L} \mathrm{IAA}$ & $0.73 \pm 0.02 \mathrm{ab}$ & $0.21 \pm 0.01 \mathrm{ab}$ & $0.94 \pm 0.03 \mathrm{ab}$ & $3.48 \pm 0.02 \mathrm{c}$ & $0.20 \pm 0.01 \mathrm{a}$ \\
$\mathrm{Cd}+100 \mu \mathrm{mol} / \mathrm{L} \mathrm{IAA}$ & $0.75 \pm 0.02 \mathrm{ab}$ & $0.22 \pm 0.00 \mathrm{a}$ & $0.97 \pm 0.03 \mathrm{a}$ & $3.41 \pm 0.01 \mathrm{bc}$ & $0.20 \pm 0.01 \mathrm{a}$ \\
$\mathrm{Cd}+200 \mu \mathrm{mol} / \mathrm{L} \mathrm{IAA}$ & $0.74 \pm 0.04 \mathrm{ab}$ & $0.21 \pm 0.01 \mathrm{ab}$ & $0.95 \pm 0.06 \mathrm{ab}$ & $3.52 \pm 0.03 \mathrm{~b}$ & $0.19 \pm 0.01 \mathrm{a}$ \\
\hline
\end{tabular}

Data represent the mean value \pm standard deviation from three replicates. Different letters within same column indicate significant differences at $P<0.05$ significance level between treatments according to the Duncan's multiple range test. Chlorophyll a/b ratio was calculated as the Chlorophyll a divided by chlorophyll $\mathrm{b}$.

\subsection{Photosynthesis Parameters}

Cd stress caused reductions of $30.28 \%(P<0.05)$ and
$38.72 \%(P<0.05)$ in $\mathrm{Pn}$ and Ls, respectively, whereas Gs, $\mathrm{Ci}$, and $\mathrm{Tr}$ were increased by $18.77 \%(P<0.05)$, $11.97 \%(P<0.05)$, and $29.74 \%(P<0.05)$, respectively, compared with the control (Table 2). After treatment with different concentration of IAA, the Pn was significantly higher than $\mathrm{Cd}$ treatment alone. The highest Pn was observed in treatment with $25 \mu \mathrm{mol} / \mathrm{L}$ IAA, but no significant difference was observed in Pn among the IAA treatments. The Gs of lettuce significantly decreased after treatment with 25 and $50 \mu \mathrm{mol} / \mathrm{L}$ IAA compared 
with $\mathrm{Cd}$ treatment alone. And the highest Gs was observed in treatment with $200 \mu \mathrm{mol} / \mathrm{L}$ IAA, which was $11.36 \%(P<0.05)$ higher than $\mathrm{Cd}$ treatment alone. Under $\mathrm{Cd}$ stress, no matter with or without IAA treatment, no significant difference in $\mathrm{Ci}$ was observed among all treatments. The trend for Tr was similar to that observed for Gs. The lowest $\operatorname{Tr}$ appeared at the IAA concentration of $50 \mu \mathrm{mol} / \mathrm{L}$, but this was not significantly difference from treatment with $100 \mu \mathrm{mol} / \mathrm{L}$ IAA. Among all of the Cd treatments, the maximum Ls was observed when the IAA concentration was $50 \mu \mathrm{mol} / \mathrm{L}$, and it was $32.34 \%(P<0.05)$ less than that of the control.

Table 2. Effects of exogenous IAA on photosynthesis parameters of lettuce under $\mathrm{Cd}$ stress.

\begin{tabular}{cccccc}
\hline IAA concentration & $\begin{array}{c}\mathrm{Pn} \\
\left(\mu \mathrm{mol} \mathrm{m}^{-2} \mathrm{~s}^{-1}\right)\end{array}$ & $\begin{array}{c}\mathrm{Gs} \\
\left(\mathrm{mol} \mathrm{m}^{-2} \mathrm{~s}^{-1}\right)\end{array}$ & $\begin{array}{c}\mathrm{Ci} \\
\left(\mu \mathrm{mol} \mathrm{mol}^{-1}\right)\end{array}$ & $\begin{array}{c}\mathrm{Tr} \\
\left(\mathrm{mmol} \mathrm{m}^{-2} \mathrm{~s}^{-1}\right)\end{array}$ & $\mathrm{Ls}$ \\
\hline Control & $14.86 \pm 0.24 \mathrm{a}$ & $0.37 \pm 0.01 \mathrm{~d}$ & $305.86 \pm 2.53 \mathrm{~b}$ & $1.95 \pm 0.03 \mathrm{~d}$ & $0.24 \pm 0.00 \mathrm{a}$ \\
$\mathrm{Cd}+0 \mu \mathrm{mol} / \mathrm{L}$ IAA & $10.36 \pm 0.17 \mathrm{c}$ & $0.44 \pm 0.01 \mathrm{~b}$ & $342.46 \pm 6.92 \mathrm{a}$ & $2.53 \pm 0.06 \mathrm{a}$ & $0.14 \pm 0.00 \mathrm{bc}$ \\
$\mathrm{Cd}+25 \mu \mathrm{mol} / \mathrm{L}$ IAA & $12.75 \pm 0.10 \mathrm{~b}$ & $0.39 \pm 0.00 \mathrm{c}$ & $332.37 \pm 5.15 \mathrm{a}$ & $2.56 \pm 0.01 \mathrm{a}$ & $0.13 \pm 0.00 \mathrm{c}$ \\
$\mathrm{Cd}+50 \mu \mathrm{mol} / \mathrm{L}$ IAA & $12.34 \pm 0.60 \mathrm{~b}$ & $0.41 \pm 0.01 \mathrm{c}$ & $323.24 \pm 7.05 \mathrm{a}$ & $2.35 \pm 0.05 \mathrm{c}$ & $0.16 \pm 0.00 \mathrm{~b}$ \\
$\mathrm{Cd}+100 \mu \mathrm{mol} / \mathrm{L} \mathrm{IAA}$ & $12.51 \pm 0.38 \mathrm{~b}$ & $0.45 \pm 0.02 \mathrm{~b}$ & $331.21 \pm 4.52 \mathrm{a}$ & $2.39 \pm 0.06 \mathrm{c}$ & $0.13 \pm 0.00 \mathrm{c}$ \\
$\mathrm{Cd}+200 \mu \mathrm{mol} / \mathrm{L} \mathrm{IAA}$ & $12.18 \pm 0.48 \mathrm{~b}$ & $0.49 \pm 0.00 \mathrm{a}$ & $335.13 \pm 5.48 \mathrm{a}$ & $2.49 \pm 0.01 \mathrm{~b}$ & $0.13 \pm 0.00 \mathrm{c}$ \\
\hline
\end{tabular}

Data represent the mean value \pm standard deviation from three replicates. Different letters within same column indicate significant differences at $P<0.05$ significance level between treatments according to the Duncan's multiple range test. Stomatal limitation (Ls) was calculated as one minus ( $\mathrm{Ci}$ divided by $\mathrm{Ca}$ ).

\section{Conclusion}

Cd stress suppressed the growth of lettuce plants by inhibiting photosynthesis characteristics. Exogenous IAA improved the photosynthetic ability in shoots of lettuce, hence, alleviated the toxic effect of $\mathrm{Cd}$ on growth. The greatest chlorophyll content was found in lettuce after foliar application of $100 \mu \mathrm{mol} / \mathrm{L}$ IAA. In summary, IAA alleviated the negative effects of $\mathrm{Cd}$ toxicity on photosynthetic in lettuce plants, which aids in a safe lettuce production in areas with Cd-contaminated soil.

\section{References}

1. Singh, S., Prasad, S. M. (2015) IAA alleviates Cd toxicity on growth, photosynthesis and oxidative damages in eggplant seedlings. Plant Growth Regul, 77: 87-98.

2. Liu, Y., Vijver, M. G., Peijnenburg, W. J. G. M. (2014). Impacts of major cations $(\mathrm{K}+, \mathrm{Na}+, \mathrm{Ca} 2+$, $\mathrm{Mg} 2+)$ and protons on toxicity predictions of nickel and cadmium to lettuce (Lactuca sativa L.) using exposure models. Ecotoxicology, 23: 385-95.

3. Beig, A. V. G., Neamati, S. H., Tehranifar, A., Emami, H. (2014) Evaluation of chlorophyll fluorescence and biochemical traits of lettuce under drought stress and super absorbent or bentonite application. Journal of Stress Physiology and Biochemistry, 10(1): 193-220.

4. Hu, W. Y., Huang, B., Shi, X. Z., Chen, W. P., Zhao, Y. C., Jiao, W. T.(2013) Accumulation and health risk of heavy metals in a plot-scale vegetable production system in a peri-urban vegetable farm near Nanjing, China. Ecotoxicology and Environmental Safety, 98: 303-09.

5. Baldantoni, D., Morra, L., Zaccardelli, M., Alfani, A. (2016) Cadmium accumulation in leaves of leafy vegetables. Ecotoxicology and Environmental Safety, 123: 89-94.

6. Wang, S. Y., Yuan, S. L., Su, L. T., Lv, A. M., Zhou, P., An, Y. (2017) Aluminum toxicity in alfalfa (Medicago sativa) is alleviated by exogenous foliar IAA inducing reduction of Al accumulation in cell wall. Environmental and Experimental Botany, 139:1-13.

7. Singh S., Prasad, S. M. (2015) IAA alleviates Cd toxicity on growth, photosynthesis and oxidative damages in eggplant seedlings. Plant Growth Regulation, 77: 87-98.

8. Hao, Z. B., Cang, J., Xu, Z. (2004) Plant physiology experiment. Harbin Institute of Technology Press, Harbin. 